\title{
Aquatic environment monitoring using a drone-based fluorosensor
}

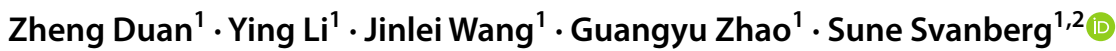

Received: 16 November 2018 / Accepted: 5 May 2019 / Published online: 25 May 2019

(C) The Author(s) 2019

\begin{abstract}
A drone-based system for monitoring of laser-induced fluorescence from the aquatic environment was constructed. Fixedrange remote-sensing demonstration measurements were performed, and field recordings of natural river water fluorescence, oil-slicks as well as dye-marked natural water volumes were taken at drone flying heights of about $10 \mathrm{~m}$. Our fluorosensor, weighing only $1.5 \mathrm{~kg}$, and carried by a commercial drone, illustrates how airborne remote sensing based on fluorescence can be made cost-effective and readily applicable, while presently only in ambient low-light-level conditions.
\end{abstract}

\section{Introduction}

Oil spills have caused worldwide attention because of major impact on marine ecosystems. Offshore drilling platform and ship accidents constitute major sources of oil spills [1]. Oil is a hydrocarbon-rich polymer mixture including cycloparaffins, alkanes, and aromatic hydrocarbons, and has very complex physical and chemical characteristics. In the first days of an oil spill, oil floats on the surface of the water. Then, under the actions of physical transport, dissolution, emulsification, oxidation, and degradation, its components change. The rapid and reliable detection and discrimination of oils are of crucial importance for marine oil-spill control.

Remote-sensing technologies have contributed much to the development of oil-spill detection [2, 3]. Several available measurement methods, for example IR/UV sensorand radar systems have been proven capable of detecting oil spills when operated from airplanes. Also, space-born equipment, such as the MODIS and MERIS satellites, were introduced and enabled oil-spill detection, also with thickness measurement capability [4].

Zheng Duan and Ying Li contributed equally to this work.

Sune Svanberg

sune.svanberg@fysik.lth.se

1 Center for Optical and Electromagnetic Research, South China Academy of Advanced Optoelectronics, South China Normal University, University City Campus, Guangzhou 510006, China

2 Department of Physics, Lund University, SE 22100 Lund, Sweden
Laser-induced-fluorescence (LIF) provides a further powerful technique for environmental monitoring. Water bodies can be studied using the characteristic fluorescence signatures of, e.g., algae and oil spills. Some early work is presented and reviewed in [5-8], with subsequent developments exemplified in [9-14]. Remote-sensing instruments using LIF techniques mostly employ pulsed laser sources with wavelengths ranging between 308 and $355 \mathrm{~nm}$ for excitation, and such instruments are also useful for vegetation monitoring (see, e.g., [15]) and also have applications in the cultural heritage sector (see, e.g., [16]). The laser-induced fluorescence approach, utilizing specific spectral signatures, provides the possibility to identify different kinds of released oil and also to studying the influence of weathering, etc. [17-20].

The available detection methods for oils are mainly designed for airborne- or satellite-borne applications. Passive imaging cameras are heavily dependent on the sunlight conditions. Reported laser-based airborne systems for fluorescence monitoring are complex and demanding. Even if an individual airborne lidar system can be applied over considerable ranges [14], it is bulky and not easy to operate. This is much related to the fact, that pulsed lasers are customarily employed, leading to heavy and costly systems, even if recently lighter-weight solutions adaptable for unmanned aerial vehicle (UAV) operation as analyzed in [20] now seem feasible.

Remote sensing of oil pollution using fluorescence has almost exclusively been pursued with pulsed laser systems, for which background radiation can conveniently be suppressed using a gated and intensified detector. With the development of $\mathrm{CW}$ blue and UV lasers based on 
semiconductor materials [21], it became possible to create simplified fluorosensors, first for laboratory studies [22] and then also for remote-sensing fluorescence applications [23]. Oil pollution discrimination by an inelastic hyperspectral Scheimpflug lidar system based on CW lasers was demonstrated in the laboratory [24] using a system which was similar to one previously used for range-resolved monitoring of algae and zooplankton in water [25]. We here report on the construction of a fully functional, compact and low-cost laser-induced fluorescence system, which is operated from a readily available commercial drone. We have recently described a drone-based, hyperspectral CW lidar system with range-resolution capability and demonstrated fluorescence height profiles of trees [26]. Drones carrying lidar systems have been used extensively, also as commercial undertakings, as discussed in [26], but as it seems only for elastic backscattering terrain and city profiling. Since rangeresolution is not required in surface monitoring, e.g., of oils on water, the optics can be adjusted for a suitable fixed flying altitude, and a fluorescence monitoring system can be made simpler and of even lighter weight.

Below, initial laboratory test measurements with the new fluorosensor, its deployment on a bridge crossing a river, as well as airborne monitoring of natural waters and contaminants using the drone are described.

\section{Instrument description}

Figure 1a shows the system integrated with a drone. We use a commercial drone (DJI M600 Pro) with a maximum lifting capacity of $6.2 \mathrm{~kg}$. It has six rotors and carries our laser-induced fluorescence system in a down-looking arrangement. An industrial computer is utilized for system control and data storage. Figure $1 \mathrm{~b}$ shows a schematic of the laser-induced fluorescence system. A continuous-wave (CW) diode laser with an output power of $1000 \mathrm{~mW}$ at a wavelength of $412 \mathrm{~nm}$ is used as the exciting source (Xinrui,
Model 412). The receiver telescope has a diameter of $50 \mathrm{~mm}$ and a focal length of $200 \mathrm{~mm}$. A $425 \mathrm{~nm}$ long-pass filter (Edmund Optics \#84-742) was in some experiments placed before the detection system to suppress the elastic scattering signal by a factor of 100 , while fully passing the fluorescence light. A compact spectrometer (Ocean Optics USB 4000) is used to detect the spectral signals continuously. The spectrometer is operating with a slit width of $200 \mu \mathrm{m}$ yielding a spectral resolution of $10 \mathrm{~nm}$. The spectral detection response was calibrated utilizing a standard tungsten light source. The drone is equipped with batteries for the drone propulsion and running of the LIF system, and allowed 25 min of continuous detection. The total weight of the fluorosensor is $1.5 \mathrm{~kg}$.

\section{Measurements}

\subsection{Fixed-range test measurements}

First, we made a test of our fluorosensor system at a fixed sensor-target separation distance of $11 \mathrm{~m}$, operating downwards from a third floor building window. The system is vertically over-looking a barrel positioned at the ground downstairs as shown in Fig. 2a. The barrel of $53 \mathrm{~cm}$ diameter is filled with tap water of $90 \mathrm{~cm}$ depth. We then studied spectral changes when hydrocarbon oil was added. Crude oils and marine diesel are the most relevant oil products in the marine environment. However, for practical reasons we instead used engine oil in our tests. The fluorescence characteristics of different oils were studied, e.g., in our very early work, referred to in [8]. Engine oil was added 15 times without stirring the water, so that the floating oil layer became thicker and thicker. Each time, $40 \mathrm{ml}$ pure oil was poured into the barrel. The total amount then ranges from 0 to $520 \mathrm{ml}$, corresponding to layers finally reaching a thickness of $2.4 \mathrm{~mm}$. The exposure time of the spectrometer is appropriately set and every spectrum is recorded with 15 times averaging. The exposure time for $0-320 \mathrm{ml}$ is set to
Fig. 1 a Drone with fluorosensor system; $\mathbf{b}$ diagram of the laser-induced fluorescence recording system

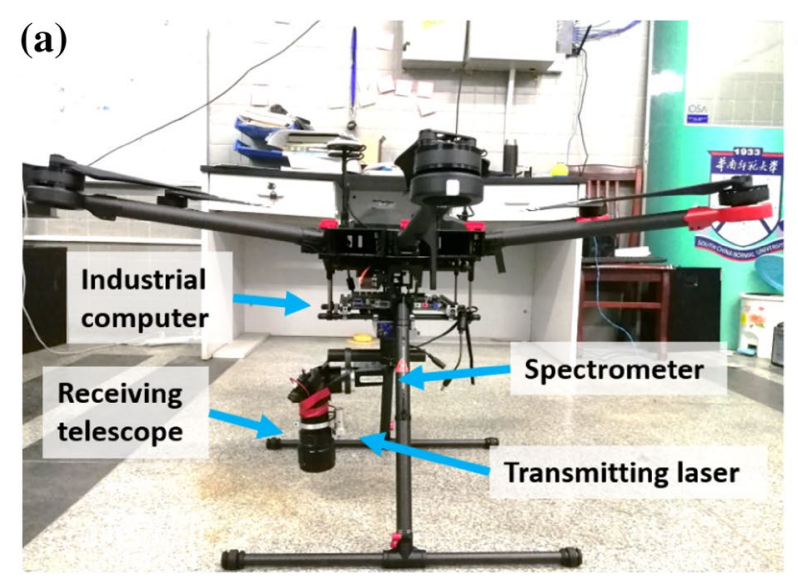

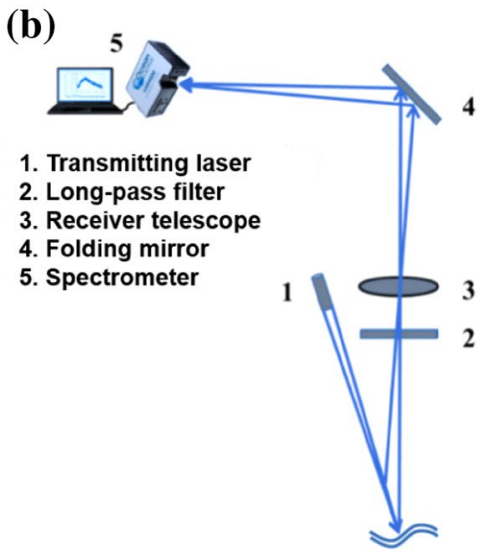


Fig. 2 a Photo of the fluorosensor measurements from the building; b remote LIF spectra following 15 different amounts of engine oil being inserted into the drum filled with water. Exposure time was $1.0 \mathrm{~s}$ for the $0-320 \mathrm{ml}$ recordings but was reduced to $0.5 \mathrm{~s}$ for the $360-520 \mathrm{ml}$ curves, finally to be set at $0.3 \mathrm{~s}$ for the pure oil
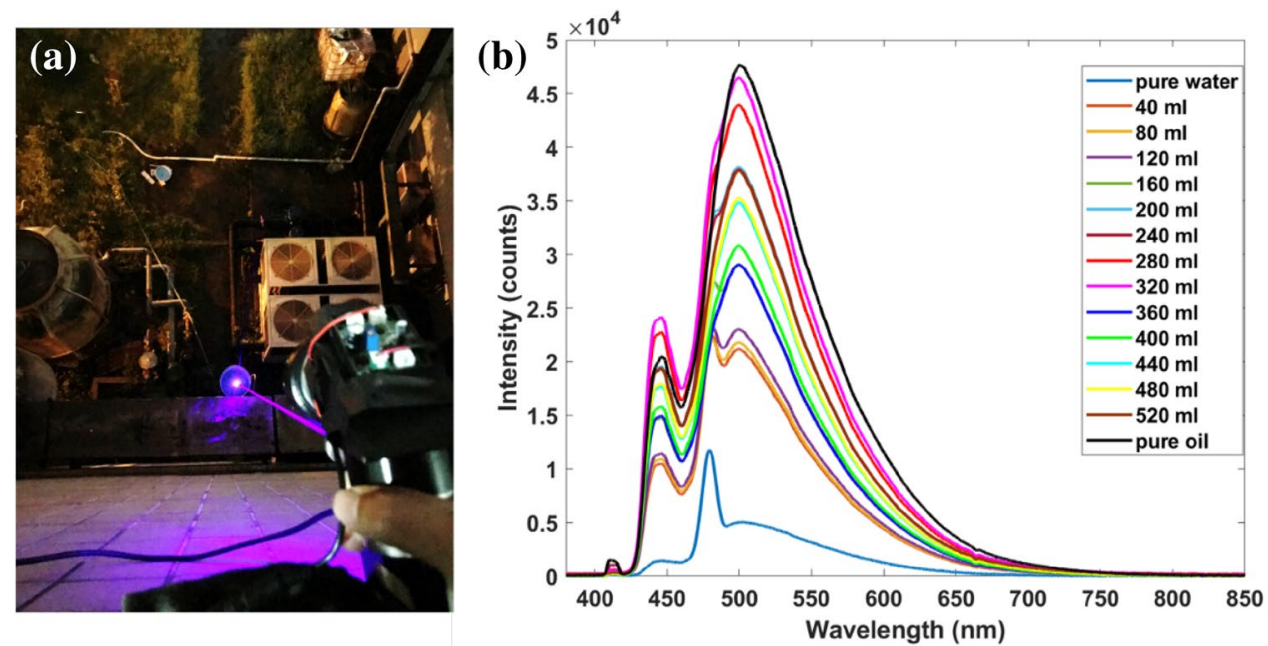

$1 \mathrm{~s}$. To avoid overexposure, from 360 to $520 \mathrm{ml}$, it is set to $0.5 \mathrm{~s}$. Finally, a measurement on pure oil was done with the exposure time set to $0.3 \mathrm{~s}$. The results of these test measurements are presented in Fig. 2b, for the listed exposure times. The spectrum recorded in the absence of oil (lower blue curve) corresponds to the water natural background fluorescence, attributed to dissolved organic matter (DOM) and peaking close to $500 \mathrm{~nm}$. In addition, the laser-induced Raman peak corresponding to the $\mathrm{O}-\mathrm{H}$ stretch vibration of the $\mathrm{H}_{2} \mathrm{O}$ molecule at a Stokes shift of about $3350 / \mathrm{cm}$ is observed at $480 \mathrm{~nm}$ for the present case of $412 \mathrm{~nm}$ excitation. The broader peak at about $440 \mathrm{~nm}$ is caused by the inherent fluorescence of the long-pass filter, which is used to cutoff the strong excitation laser of $412 \mathrm{~nm}$. In the later field measurements the filter was removed and thus this spurious signal contribution.

From the spectral curves, the characteristic and increasing fluorescence peak of the engine oil can be observed, again peaking at around $500 \mathrm{~nm}$. It is superimposed on the broad DOM fluorescence distribution. With the increasing amount of oil, the water Raman peak becomes smaller and is finally hard to discern in the presence of the strong oil fluorescence. This is because of the oil absorption of the $412 \mathrm{~nm}$ radiation, preventing light to reach the underlaying water. At the same time the oil fluorescence increases and soon strongly dominates over DOM fluorescence. To show the spectral development, the ratio between F500 and F480 intensities is formed, as is shown in Fig. 3b. The oil fluorescence peak intensity extracted from the spectra, is presented in Fig. 3c while the strength of the water Raman peak is plotted in Fig. 3d.

The process method of the recorded data is illustrated in Fig. 3a. C (F500) is the oil fluorescence at 500 nm. A (F480) is the fluorescence intensity at $480 \mathrm{~nm}$ and $\mathrm{B}$ is the freestanding water Raman signal. The increasing ratio between F500 and F480 is observed in Fig. 3b, where the $10 \mathrm{ml}$ and $20 \mathrm{ml}$ data points were measured in a separate test. The ratio gets saturated with more oil added. In the evaluation of the oil fluorescence, shown in Fig. 3c, the fluorescence intensity at $500 \mathrm{~nm}$ is used directly, since the DOM contribution becomes very small for thicker layers. To get the absolute (free-standing) water Raman peak intensity from our measured results, first, we set the intensity values at the characteristic water Raman band (470-490 nm) to zero. We then used the method of interpolation in the curve fitted to the non-Raman parts of the composed spectrum, also considering the filter fluorescence, for achieving a background spectrum. Then, the resulting background spectra were subtracted from the measured spectra to get the absolute Raman peak. The result is shown in Fig. 3d. To compensate for different exposure time to get everything on the same scale, the spectral intensities are normalized to the different exposure times used as mentioned at the beginning of Sect. 2.1. We note, that even for relatively thick oil films the oil fluorescence still increases and there is a remaining water Raman signal, reflecting the fact that oil has a comparatively low absorption at the $412 \mathrm{~nm}$ wavelength. The curves have some irregularities, most likely due to possible instability in the experimental set-up reaching over three building stories.

\subsection{Bridge-based measurements on river water}

We performed measurements from a bridge over the Zhujiang river (Pearl River) in Guangzhou conducted with the fluorosensor to obtain more realistic conditions. The detection distance was $9 \mathrm{~m}$. The natural Zhujiang water and a floating shallow container filled with pure oil are both measured with the exposure time of $0.5 \mathrm{~s}$. The container is $90 \mathrm{~cm}$ in diameter and $25 \mathrm{~cm}$ in height. At the bottom of the container, a black cloth is placed. The measurement results, which like in all the following registrations, were obtained in the absence of the blocking colored-glass filter, are presented in Fig. 4. 

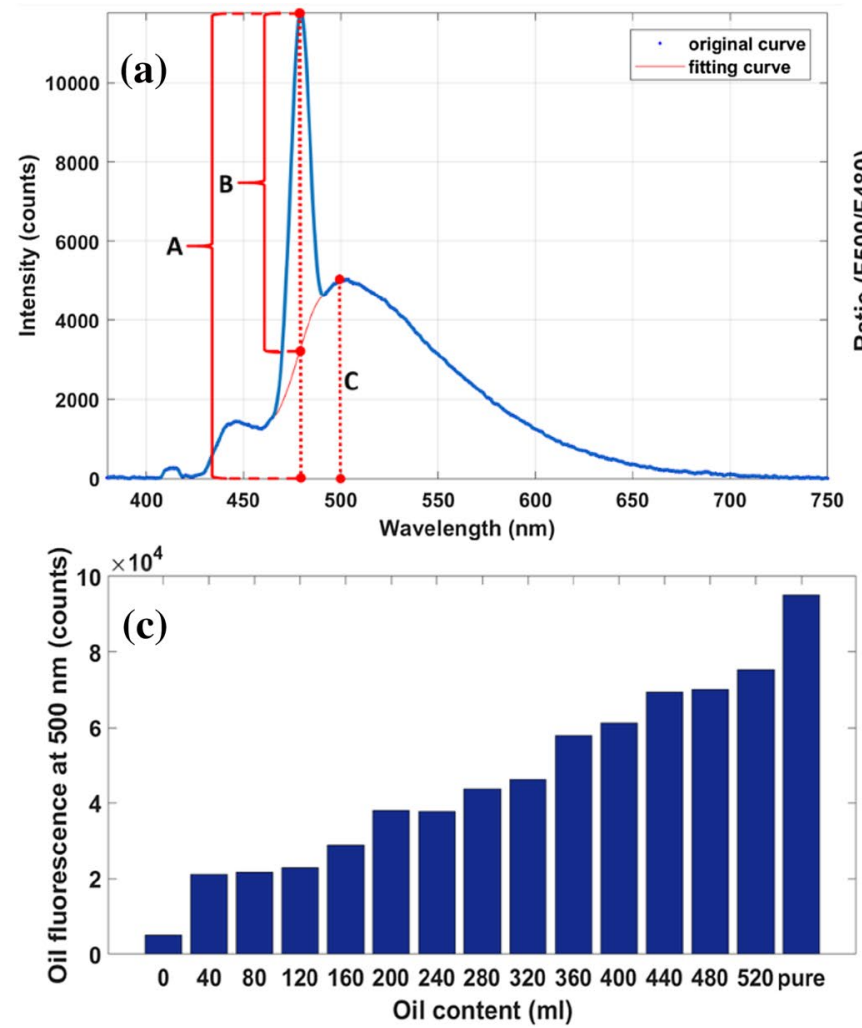

Fig. 3 a Extraction of free-standing water Raman signal in the presence of DOM/oil and filter fluorescence; $\mathbf{b}$ bar graph of the ratio between 500 and $480 \mathrm{~nm}$; $\mathbf{c}$ bar graph of oil fluorescence at $500 \mathrm{~nm}$.

Figure $4 \mathrm{a}$ is the schematic graph of the bridge-based arrangements, and Fig. $4 \mathrm{~b}$ is a photograph of the laser beam striking the river surface. Figure $4 \mathrm{c}$ shows the spectra recorded by the fluorosensor. The natural river deep water fluorescence shows a strong DOM signal from the polluted water, as well as a prominent chlorophyll peak at around $680 \mathrm{~nm}$ due to the abundant microscopic algae in the eutrophic water. The water Raman peak is observed at $480 \mathrm{~nm}$, as induced by the $412 \mathrm{~nm}$ laser, and provides a convenient calibration, since the probed water volume is the same. This allows the observation, that the river water has about six times stronger DOM signal than Guangzhou tap water, the spectrum of which is included in Fig. $2 \mathrm{~b}$. When the floating container with oil is brought under the fluorosensor laser beam, the broad-band fluorescence increases about five times and Raman and algal signals disappear as expected. It should be noted, that in the open maritime environment, with a much lower DOM signal, the contrast to an oil spill is clearly much enhanced, and can be further increased by selecting an optimized, considerably lower, excitation wavelength, where the oil has a much higher absorption.
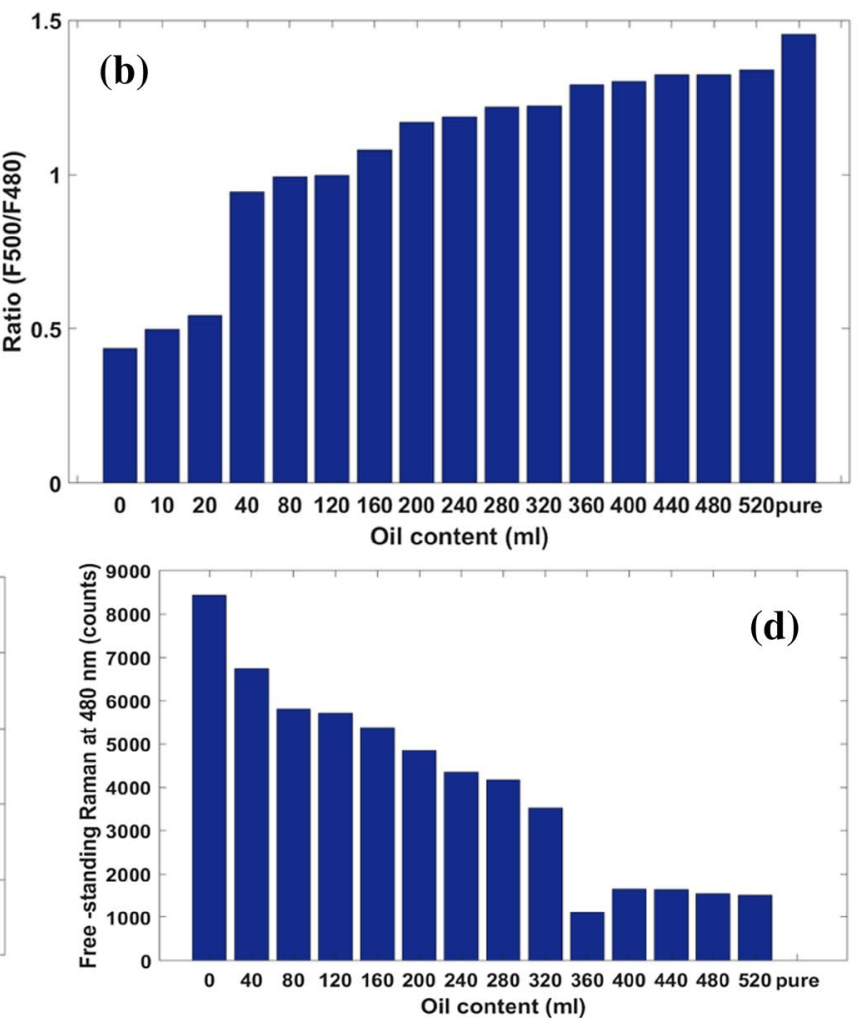

The residual observed in the absence of oil is due to the weak DOM signal d bar graph of the water Raman intensity at $480 \mathrm{~nm}$

\subsection{Drone-based measurements of river water}

The drone-based measurements were performed over the Zhujiang river with the fluorosensor mounted under the drone. The exposure time is set to $0.5 \mathrm{~s}$. To avoid polluting the river, we again fix two floating containers on the surface of the river as shown in Fig. 5a. The yellow spot marks the container filled with 11 of pure oil, resulting in a typical layer thickness of 1-2 mm. The red spot indicates another container filled with 101 of a dilute solution of Rhodamine 610 dye with the concentration of $0.03 \mathrm{~g} / \mathrm{l}$. The dye is dissolved in natural Zhujiang river water, and the resulting layer thickness is $1-2 \mathrm{~cm}$. The flight route is set including four times back and forth covering an area of $10 \mathrm{~m} \times 20 \mathrm{~m}$ (length $\times$ width) with the average drone flight speed of about $3 \mathrm{~km} / \mathrm{h}$. The measurement scene is shown in Fig. $5 \mathrm{~b}$.

The measurement results are presented with four typical spectra in Fig. 6a. The oil fluorescence at $500 \mathrm{~nm}$ and the characteristic peak of the dye at $580 \mathrm{~nm}$ are observed in the measurements on the two floating containers. The drone scan also covers the bushes on the riverside and the strong chlorophyll peaks at $685 \mathrm{~nm}$ and $745 \mathrm{~nm}$, characteristics of terrestrial vegetation, are recorded. The natural 


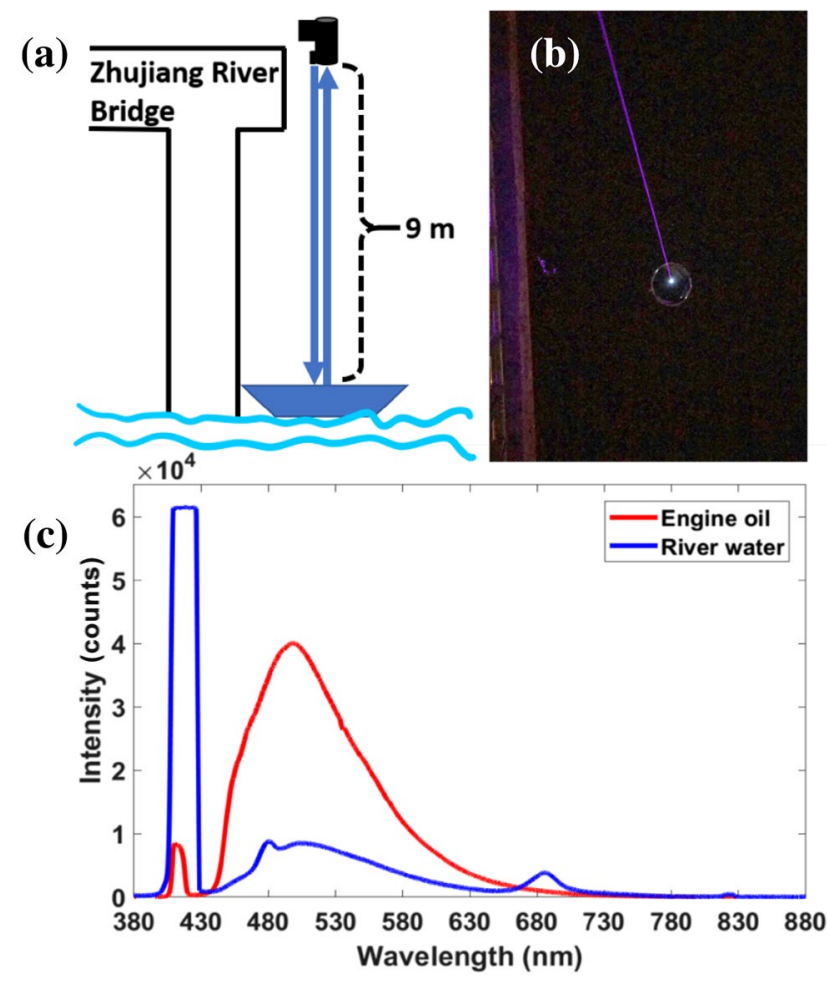

Fig. 4 a Schematic arrangement of the fluorosensor system measurement from the Zhujiang bridge; b photograph showing elastic backscattering from the exciting $412 \mathrm{~nm}$ beam and the whitish oil fluorescence of the river surface; $\mathbf{c}$ LIF spectra of Zhujiang deep water and engine oil in the floating container

Zhujiang deep-water LIF spectrum is expanded in Fig. 6b with the water Raman peak at $480 \mathrm{~nm}$. DOM fluorescence and the algal chlorophyll signal from the water emerge prominently, and as expected similarly as in Fig. 4b, as normalized on the water Raman peak.

Figure 7 shows the results of a slow linear scan of the drone flying over the oil-filled container on the Zhujiang river. The time duration is $50 \mathrm{~s}$ and each recording has an exposure time of $0.5 \mathrm{~s}$. We notice a very prominent oil fluorescence signal as compared to the surrounding water chlorophyll signal (which is lost when the oil signal appears).

In further measurements, we monitored the diffusion of a localized release of dye into the surface water of the Zhujiang river. A bucket of 4.51 of water containing a concentration of $0.03 \mathrm{~g} / \mathrm{l}$ of Rhodamine 610 dye was poured into the Zhujiang river from the bridge, while the drone was hovering down-stream over the river with the fluorosensor constantly recording. The exposure time of the spectrometer was set to $0.5 \mathrm{~s}$. The drone was flying at a height of $10 \mathrm{~m}$ and $5 \mathrm{~m}$ away from the point of the dye pouring as shown in Fig. 8a. Figure 8b shows examples of spectra recording from the measurement sequence.

Figure 9 shows a full drone-based temporal recording of the Zhujiang water, while a bucket of dye-containing water $(0.03 \mathrm{~g} / \mathrm{l})$ was poured into the river in a similar way as just discussed. The time duration is about $80 \mathrm{~s}$ and the exposure time of the spectrometer was $0.5 \mathrm{~s}$. By comparing the dye signal in Fig. 9 to the one in Fig. 6a, scaling with the typical interrogated layer thickness, and normalizing on the reasonable stable river algal fluorescence, we obtain a sensitivity of about $10 \mu \mathrm{g} / \mathrm{l}$, which could become one order of magnitude better if choosing an excitation wavelength much better overlapping the dye absorption profile.

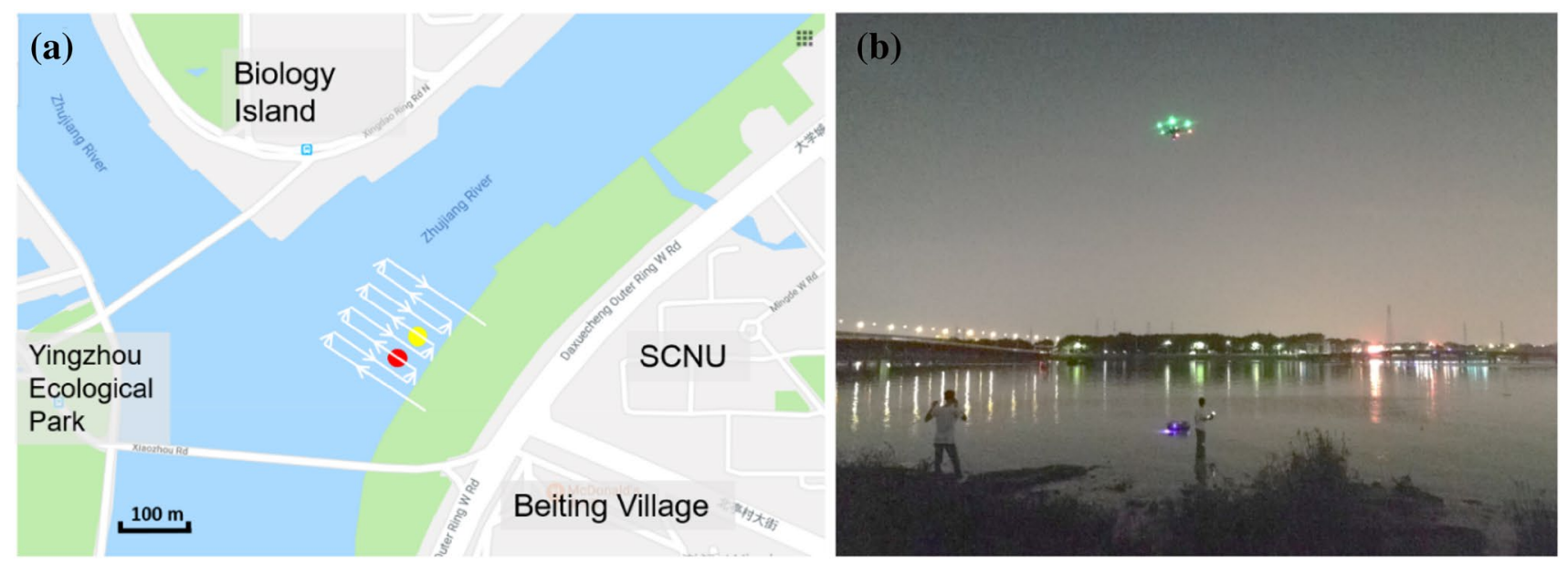

Fig. 5 a Map of the drone-based fluorosensor scanning over the Zhujiang river; b photo of the in situ measurements with the drone flying over the river and the exciting laser beam hitting the surface and inducing fluorescence 


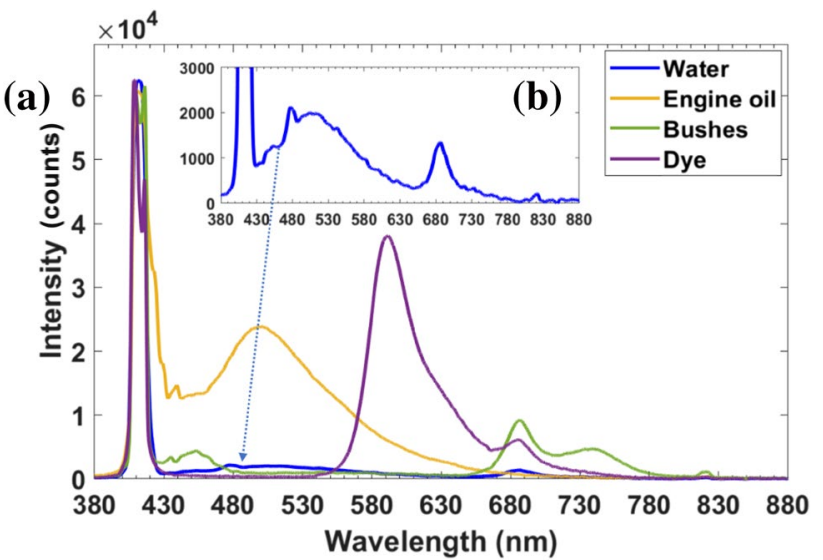

Fig. 6 a Spectra captured by the drone-based fluorosensor system over the Zhujiang river; $\mathbf{b}$ expanded LIF spectrum of Zhujiang water. We note, that by utilizing all spectra of this kind, recorded along the path indicated in Fig. 5a, a very crude "map" of the $200 \mathrm{~m}^{2}$ area could have been constructed

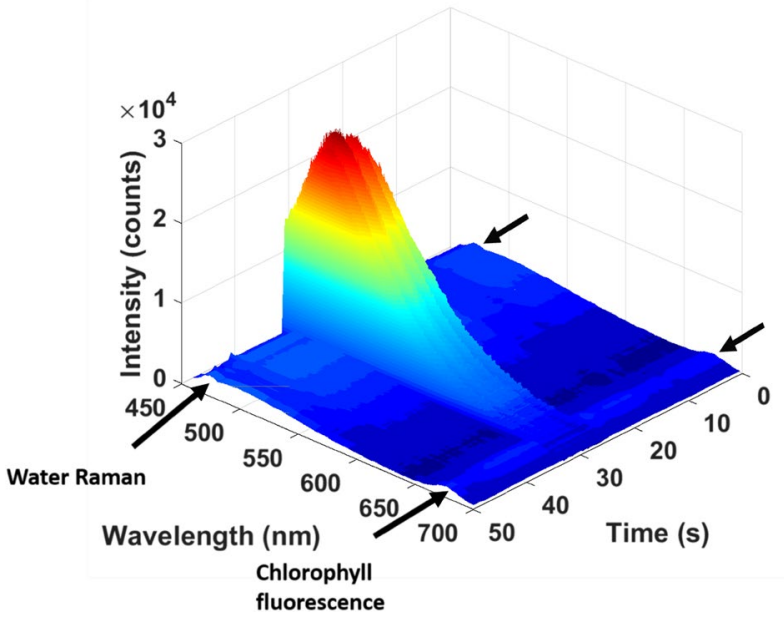

Fig. 7 2D map of the linear scan of the oil-filled container based on the drone

\section{Discussion}

We have described a compact and light-weight fluorosensor, which provides high-quality fluorescence spectra of the superficial aquatic layer featuring spectral signatures from oils, dissolved organic matter (DOM), algae, etc., and allowing internal calibration using the water Raman signal [27, 28]. The full system weight is only $1.5 \mathrm{~kg}$, achievable using a high-power $\mathrm{CW}$ semiconductor laser in conjunction with a compact digital spectrometer. The system was integrated with a compact drone carrier. To obtain range-resolved spectra of the upper few meters of the water overflown by the drone, a CW lidar system based on the Scheimpflug principle, as described for vegetation monitoring in our recent paper [26], could be adapted to aquatic applications, where many challenges regarding, e.g., the aquatic fauna are present [29]. However, for studies of oil on water, and for hydrological studies of dye dispersion [30], the compact system described in the present paper provides a good alternative to conventional pulsed-laser fluorosensors and CW-laser Scheimpflug systems, and exhibits certain advantages in terms of performance and simplicity. With a CW semiconductor laser operating just below $400 \mathrm{~nm}$, an eyesafe system would be achievable. The present version of the fluorosensor system could only be used at night time, which is a clear drawback compared to pulsed lidar systems with range gating, allowing daytime use, while again still functioning better in low ambient light level conditions. Using sufficiently high CW powers and combining with a suitable modulation scheme for background subtraction, daylight operation should be feasible, considerably extending the present capability. Clearly, limited range and flying duration constitute limitations for large-area surveillance. However, our study shows that the cost of airborne fluorescence mapping can be dramatically reduced, making the drone-based remote LIF technique a viable diagnostic alternative, especially in studies of limited areas.
Fig. 8 a Photo of the fixed-point scanning of the Zhujiang water while pouring a bucket of water with a small amount of Rhodamine 610 dye $(0.03 \mathrm{~g} / \mathrm{l})$ from the bridge, the railing of which can be seen in the lower right corner; b spectra recorded from the drone, observing the event, with the algal signal constant while the dye is being naturally diluted
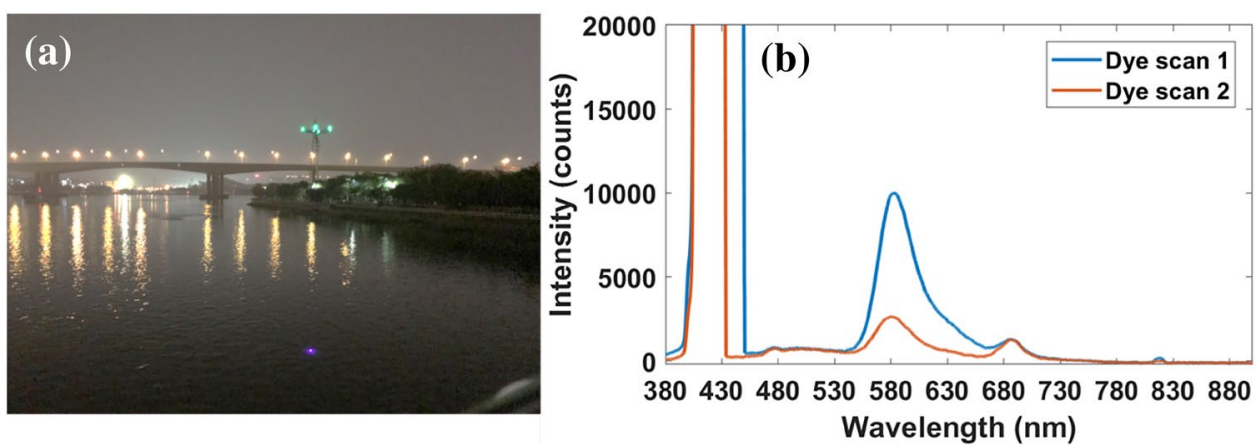


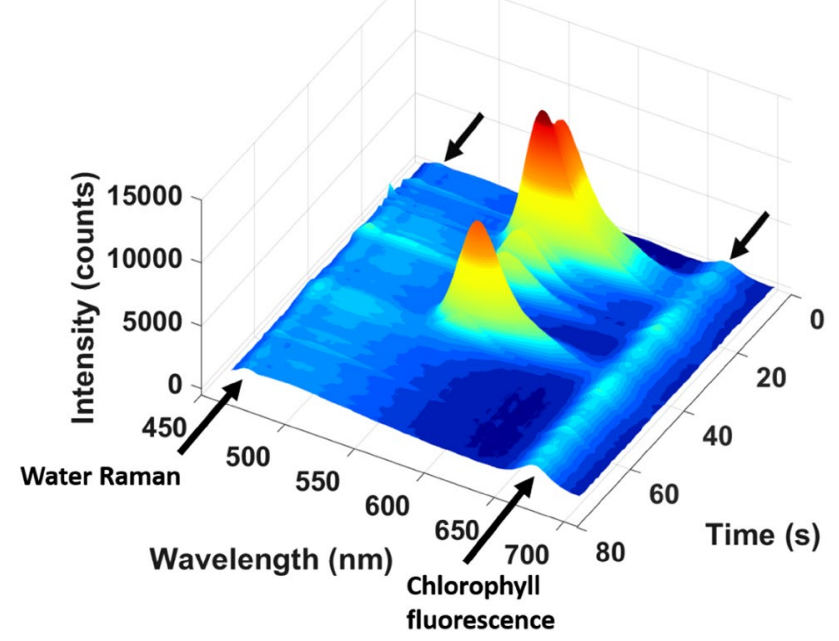

Fig. 9 2-D map of drone-based scanning of the Zhujiang water while pouring a bucket of water with a small amount of Rhodamine 610 dye $(0.03 \mathrm{~g} / \mathrm{l})$. The drone is hoovering, while the river water is flowing under it

Acknowledgements The authors gratefully acknowledge the continuing support from Professors Sailing He and Guofu Zhou and the assistance by Xun Wang. This work was supported by the National Science Foundation of China (61705069) and the Chinese Ministry of Science and Technology through the National Key Research and Development Program of China (2018YFC1407503) and the Special Funds Program for the Cultivation of Guangdong College Students' Scientific and Technological Innovation Climbing Project (pdjha0127).

Open Access This article is distributed under the terms of the Creative Commons Attribution 4.0 International License (http://creativeco mmons.org/licenses/by/4.0/), which permits unrestricted use, distribution, and reproduction in any medium, provided you give appropriate credit to the original author(s) and the source, provide a link to the Creative Commons license, and indicate if changes were made.

\section{References}

1. S.E. Chang, J. Stone, K. Demes, M. Piscitelli, Consequences of oil spills: a review and framework for informing planning. Ecol. Soci. 19, 26 (2014)

2. R. Goodman, Overview and future trends in oil spill remote sensing. Spill Sci. Technol. Bull. 1, 11 (1994)

3. M. Fingas, C.E. Brown, Chap. 6. Oil spill remote sensing: a review, in Spill science and technology, ed. by M. Fingas (Gulf Professional Publishing, Boston, 1990)

4. A. Pisano, F. Bignami, R. Santoleri, Oil spill detection in glintcontaminated near-infrared MODIS imagery. Remote Sens. 7, $1112(2015)$

5. J.F. Fantasia, H.C. Ingrao, The development of an experimental airborne laser remote sensing system for the detection and classification of oil spill. In: Ann Arbor, Michigan. In: Proc. 9th International Conference on Remote Sensing of Environment, p. 1711 (1974)
6. F.E. Hoge, R.N. Swift, Oil film thickness measurement using airborne laser-induced water Raman backscatter. Appl. Opt. 19, 3269 (1980)

7. S. Svanberg, Lasers as Probes for Air and Sea. Contemp. Phys. 21, 541 (1980)

8. S. Svanberg, Laser fluorescence spectroscopy in environmental monitoring, in Optoelectronics for environmental science, ed. by S. Martellucci, A.N. Chesters (Plenum Press, New York, 1990), pp. 15-27

9. C.E. Brown, M.F. Fingas, Review of the development of laser fluorosensor for oil spill application. Mar. Pollut. Bull. 47, 477 (2003)

10. M. Sasano, K. Hitomi, H. Yamanouchi, S. Yamagishi, Remote sensing of oil spills with a helicopter-based fluorescence imaging lidar. Trans. Vis. Soc. Jpn. 25, 421 (2005)

11. M. Lennon, N. Thomas, V. Mariette, S. Babichenko, Operational quantitative mapping of oil pollutions at sea by joint use of a hyperspectral imager and a fluorescence lidar system on-board a fixed-wing aircraft. Oceans 842, 848 (2005)

12. V. Drozdowska, Seasonal and spatial variability of surface seawater fluorescence properties in the Baltic and Nordic Seas: results of lidar experiments. Oceanologia 49, 59 (2007)

13. A.A. Lübben, Z.O. Dellwig, S. Koch, M. Beck, T.H. Badewien, S. Fischer, R. Reuter, Distributions and characteristics of dissolved organic matter in temperate coastal waters (southern North Sea). Ocean Dyn. 59, 263 (2009)

14. C.E. Brown, Chap. 7 Laser fluorosensors, in Oil spill science and technology, ed. by M. Fingas (Gulf Professional Publishing, Boston, 2011)

15. S. Svanberg, Fluorescence lidar monitoring of vegetation status. Phys. Scr. T58, 79 (1995)

16. V. Raimondi, G. Cecchi, D. Lognoli, L. Palombi, R. Grönlund, A. Johansson, S. Svanberg, K. Barup, J. Hällström, The fluorescence LIDAR technique for the remote sensing of photoautotrophic biodeteriogens on outdoor cultural heritage: a decade of in situ experiments. Int. Biodeterior. Biodegrad. 63, 823 (2010)

17. A.B. Utkin, A. Lavrov, R. Vilar, Evaluation of oil spills by laser induced fluorescence spectra. Proc. SPIE 7994, 48 (2010)

18. W. Feng, R. Wang, P. Sun, Z. Gao, L. Chen, Study on ultraviolet laser induced fluorescence spectra of several typical petroleum contaminants. Spectrosc. Spectr. Anal. 31, 1168 (2011)

19. M.D.C. Martín, N.V. Yarovenko, C.P. Gómez, J.L.L. Soto, J.M.T. Palenzuela, Oil pollution detection using spectral fluorescent signatures (SFS). Environm. Earth Sci. 73, 2909 (2015)

20. V. Raimondi, L. Palombi, D. Lognoli, A. Masini, E. Simeone, Experimental tests and radiometric calculations for the feasibility of fluorescence LIDAR-based discrimination of oil spills from UAV. Int. J. Appl. Earth. Obs. Geoinform. 61, 46 (2017)

21. S. Nakamura, Background story of the invention of efficient InGaN blue-light-emitting diodes (Nobel lecture). Angew. Chem. Int. Ed. 54, 7770 (2015)

22. U. Gustafsson, S. Pålsson, S. Svanberg, Compact fiber-optic fluorosensor using a continuous-wave violet diode laser. Rev. Sci. Instr. 71, 3004 (2000)

23. M. Brydegaard, A. Merdasa, A. Gebru, H. Jayaweera, S. Svanberg, Realistic instrumentation platform for active and passive optical remote sensing. Appl. Spectrosc. 70, 372 (2016)

24. F. Gao, J. Li, H. Lin, S. He, Oil pollution discrimination by an inelastic hyperspectral Scheimpflug lidar system. Opt. Express 25, 25515 (2017)

25. G.Y. Zhao, M. Ljungholm, E. Malmqvist, G. Bianco, L.A. Hansson, S. Svanberg, M. Brydegaard, Inelastic hyperspectral lidar for profiling aquatic ecosystems. Lasers Photon. Rev. (2016). https://doi.org/10.1002/lpor.201600093 
26. X. Wang, Z. Duan, M. Brydegaard, S. Svanberg, G.Y. Zhao, Drone-based area scanning of vegetation fluorescence height profiles using a miniaturized hyperspectral lidar system. Appl. Phys. B 124, 207 (2018). (APHB-D-18-00319)

27. H. Edner, J. Johansson, S. Svanberg, E. Wallinder, G. Cecchi, L. Pantani, Fluorescence lidar monitoring of the Arno river. EARSEL Adv. Rem. Sens. 1, 42 (1992)

28. A.J. Lawaetz, C.A. Stedmon, Fluorescence intensity calibration using the Raman scatter peak of water. Appl. Spectrosc. 63, 936-940 (2009)
29. M. Brydegaard, S. Svanberg, Photonic monitoring of atmospheric and aquatic fauna. Lasers Photon. Rev. 12, 1800135 (2018)

30. M.A. Sundermayer, E.A. Terray, J.R. Ledwell, A.G. Cunningham, P.E. Larocque, J. Banic, W.J. Lillycrop, Three-dimensional mapping of fluorescent dye using a scanning, depth-resolving airborne lidar. 1050 J. Atmos. Ocean. Tech. 24, 1050 (2007)

Publisher's Note Springer Nature remains neutral with regard to jurisdictional claims in published maps and institutional affiliations. 